\title{
Energy Efficient Enhancement and Initial Cost Saving Mechanisms for Petrochemical Manufacturing Industrial Applications
}

\section{Dr. Boselin Prabhu SR ${ }^{1 *}$ and Balakumar $\mathbf{N}^{2}$}

${ }^{1}$ Department of Electrical and Electronics Engineering, Tamilnadu College of Engineering, Coimbatore, India ${ }^{2}$ Department of Electronics and Communication Engineering, SVS College of Engineering, Coimbatore, India

\section{Introduction}

Energy plays a major role in all the petro-chemical industrial applications because it involves the initial cost. All the petro chemical industry produces a large volume and intermediary organic chemicals as well as large volume of plastics. Energy efficient enhancement is a significant way to decrease these cost and to increase the expectable earnings. Majority of opportunities are available at industrial plants in the USA petro chemical industry to decrease energy consumption in a cost effective manner.

Energy use is also a main source of emissions in the petro chemical industry creating energy efficiency enhancement an attractive chance to reduce emissions and initial operating costs. Energy efficient should be a significant component of an industry environmental approach. Energy efficient investment is complete business approach in today's manufacturing environment. Energy is a very vital cost factor in the petro chemical industry in general and the Petro chemical industry is even more energy exhaustive than other sub-sectors within the petro chemical industry. The USA petro chemical industry is the largest chemical industry in the world [1].

The USA chemical industry is the foremost chemical industry in the world. In this industry more than seven thousand different combinations are created with production volumes ranging from a few grams to billions of pounds. From diversity of the industry, it can be suitable to subdivide the chemical industry into various subgroups. One probable division is the division between the organic and inorganic chemicals industry. In this inorganic chemical industry, chemical products are created from non-carbon elements taken from the earth such as phosphor nitrogen and chlorine.

In this USA, Organic chemical industry, hydrocarbon resources for the chemical industry are used to yield about 10 base products. Nearly $95 \%$ of organic products today are created from oil and natural gas derived raw materials, with a decreasing share being created from coal and a growing but still very small share from biomass raw materials. The raw materials are further processed to various intermediary and final products by presenting functional groups to the raw materials.

\section{Petrochemical manufacturing industry}

This industry includes establishments principally involved manufacturing acyclic hydrocarbons such as ethylene, propylene, and butylene made from refined petroleum and manufacturing cyclic aromatic hydrocarbons such as toluene, styrene, xylene, ethyl benzene, and cumene made from refined petroleum or liquid hydrocarbons.

\section{Plastic material and resin manufacturing industry}

This industry includes establishments primarily engaged in manufacturing resins, plastics materials, and non-vulcanizable thermoplastic elastomers and mixing and blending resins on a custom basis, and manufacturing non-customized synthetic resins.

\section{Methodology for estimating energy efficiency improvement}

The indicator study makes use of a Top-down approach in order to evaluate the energy saving potential and $\mathrm{CO}_{2}$ emission decreases by comparing the current performance of the sector to Best Practice Technology (BPT). To these end BPT energy use is associated with current energy use according to IEA energy figures [2]. From this data the choice has been made to estimate the energy saving potentials using best practice technology (BPT) instead of best available techniques (BAT). BPT signifies the most advanced technologies that are presently in use at industrial scale and they are therefore, by definition, economically viable. In contrast, best available techniques (BAT) are commonly more advanced in terms of the technology level but their large-scale viability is not always certain. In certain cases, both are identical each other.

\section{Conclusion}

The approach for calculating the energy efficient enhancement potentials in the chemical and petrochemical sector consists of, first the production volumes are multiplied by BPT values in order to estimate the smallest achievable energy use linked with each process at the country level. By comparison of the resulting total with the total energy use of the chemical and petrochemical sector described in the IEA energy statistics an energy efficiency index (EEI) is established.

\section{References}

1. Neelis M, Worrell E, Masanet E (2008) Energy efficiency improvement and cost saving opportunities for the petrochemical industry. Environmental Energy Technologies Division. Ernest Orlando Lawrence Berkeley National Laboratory, University of California, Berkeley, CA.

2. Saygın D, Patel MK, Tam C, Gielen DJ (2009) International Energy Agency (IEA): Chemical and petrochemical sector: Potential of best practice technology and other measures for improving energy efficiency, IEA information paper.

"Corresponding author: Dr. Boselin Prabhu SR, Assistant Professor, Department of Electrical and Electronics Engineering, Tamilnadu College of Engineering, Coimbatore, India, Tel: +91-9790100467; E-mail: eben4uever@gmail.com

Received February 04, 2017; Accepted February 15, 2017; Published February 20, 2017

Citation: Boselin Prabhu SR, Balakumar N (2017) Energy Efficient Enhancement and Initial Cost Saving Mechanisms for Petrochemical Manufacturing Industrial Applications. J Pet Environ Biotechnol 8: e131. doi: 10.4172/2157-7463.1000e131

Copyright: (C) 2017 Boselin Prabhu SR, et al. This is an open-access article distributed under the terms of the Creative Commons Attribution License, which permits unrestricted use, distribution, and reproduction in any medium, provided the original author and source are credited. 